\title{
GT2005-68702
}

\section{ONLINE WATER WASH TESTS OF GE J85-13}

\author{
Elisabet Syverud and Lars E. Bakken \\ NTNU, Norwegian University of Science and Technology, \\ Department of Energy and Process Engineering, N-7491 Trondheim, Norway
}

\section{ABSTRACT}

This paper reports the results of a series of online water wash tests of a GE J85-13 jet engine at the test facilities of the Royal Norwegian Air Force. The engine performance was deteriorated by injecting atomized saltwater at the engine inlet. Then the engine was online washed with water injected at three different droplet sizes $(25,75$ and $200 \mu \mathrm{m})$ and at water-to-air ratios ranging from $0.4 \%$ to $3 \%$ by mass. Engine performance was measured using standard on-engine instrumentation. Extra temperature and pressure sensors in the compressor section provided additional information of the propagation of deposits in the aft stages. The measurements were supported by visual observations.

The overall engine performance improved rapidly with online wash. The build-up of deposits in the aft stages was influenced both by the droplet size and the water-to-air ratio. The water-to-air ratio was the most important parameter to achieve effective online washing.

Keywords: Compressor cleaning, axial compressor, stage characteristics, GE J85-13

\section{INTRODUCTION}

Online water washing has become increasingly important with operators of industrial gas turbines due to the potential for reduced degradation rate and increased operating intervals. Successful online washing requires close attention to the gas turbine flow path geometry, the operating profile and the nature of the airborne fouling at the compressor inlet (after filtration).

Several manufacturers offer online washing equipment and there exists many patents on gas turbine water wash. There is currently no consensus on a recommended method for effective online water washing. System properties like droplet size, droplet velocity and fluid injection rate vary from one system to another. This makes it difficult for operators to select the best online water wash system for their application. Two recent publications give a historical review of online washing systems and a classification of available systems [1,2].

Today's online washing equipment for aeroderivative engines can be categorized in two main pressure ranges: Fluid pressures up to 10 bar are considered low pressure systems, while high pressure systems have fluid pressures above 50 bar. The atomized droplets produced by high pressure systems have a droplet diameter typically less than $150 \mu \mathrm{m}$ and resembles the water occurring naturally in clouds and fog. Low pressure systems will have larger, drizzle-like droplets with diameter ranging from 100 to $500 \mu \mathrm{m}$ and larger. Low pressure systems with air assisted nozzles will generate smaller droplet sizes, resembling the droplets of the high pressure systems. Large droplets may cause blade erosion in the compressor. [2-5]

The fluid injection rate (water-to-air ratio) has an impact on the internal surface wetting of the compressor. Due to possible control instabilities, flame-out, or blade erosion the water-to-air ratio has generally been kept low. A typical online washing system for aeroderivative engines has fluid injection in the range from $0.2 \%$ to $0.8 \%$ (mass based) [2-5].

The flow field within an axial compressor subject to water injection is complex to predict due to the two-phase nature of the flow. The motion of water droplets inside axial compressors was studied by Marchik [6] and Tsuchiya and Murthy[7]. While Marchik studied droplets smaller than $70 \mu \mathrm{m}$, Tsuchiya and Murthy tested a six stage axial compressor with water injection rates up to $15 \%$ and with droplets of 90 and $600 \mu \mathrm{m}$. Several papers offer theoretical approaches to wet compression[8-10]. These studies are related to tiny droplets, less than $15 \mu \mathrm{m}$, with no velocity slip between the droplet and air. A study of the effects on gas turbines of naturally occurring water in the atmosphere is given by AGARD [11] and gives additional insight into the operating limitations of gas turbine engines.

To understand and reveal the mechanisms related to online water washing a systematic test campaign was performed on a GE 885-13 jet engine. The engine performance was deteriorated 
by injecting atomized saltwater at the engine inlet and the engine performance was restored using online water washing. The water was injected at three different droplet sizes $(25,75$ and $200 \mu \mathrm{m}$ ) at water-to-air ratios from $0.4 \%$ to $3 \%$ by mass. The cleaning effectiveness was measured in terms of improved engine performance using standard on-engine instrumentation. In addition, extra temperature and pressure sensors installed in the compressor section provided added information on the propagation of the deposits into the engine. The measurements were supported by visual observations through the borescope and by laboratory analysis of the stator vane deposits. The results of the axial compressor deterioration are reported by Syverud, Brekke and Bakken [12], and that paper should be seen in context with the present work. The test facilities, the GE J8513 engine and its initial condition, the engine instrumentation and the deterioration method is described in the present paper only when required for completeness.

\section{NOMENCLATURE}

A

$c_{p}$

$\mathrm{C}$

CIT

CIP

GE

IGV

ISO

$\dot{\mathrm{m}}$

$\mathrm{N}$

NASA

$\mathrm{P}$

$\mathrm{r}$

$\mathrm{R}$

R.H.

RNoAF

RTD

$\mathrm{T}$

U

$\mathrm{V}$

w/a

$\alpha$

$\beta$

$\rho$

$\eta$

$\gamma$

$\Psi^{\mathrm{T}}=\mathrm{c}_{\mathrm{p}} \Delta \mathrm{T}_{\mathrm{t}} / \mathrm{U}_{\text {tip }}{ }^{2}$

$\Phi=\mathrm{C}_{\mathrm{a}} / \mathrm{U}_{\text {tip }}{ }^{2}$

Subscripts

a

$\mathrm{amb}$
Flow area, $\left[\mathrm{m}^{2}\right]$

Specific heat at const. pressure, $[\mathrm{kJ} / \mathrm{kgK}]$

Absolute air velocity, $[\mathrm{m} / \mathrm{s}]$

Compressor inlet temperature, $[\mathrm{K}]$

Compressor inlet pressure, $[\mathrm{kPa}]$

General Electric

Inlet guide vanes

Int. Organization for Standardization $\left(^{*}\right.$ )

Mass flow rate, $[\mathrm{kg} / \mathrm{s}]$

Shaft speed, [rpm]

National Aeronautics and Space

Administration

Pressure, $[\mathrm{kPa}]$

Blade radius, $[\mathrm{m}]$

Gas constant, $[\mathrm{kJ} / \mathrm{kgK}]$

Relative humidity, [\%]

Royal Norwegian Air Force

Resistance temperature detector

Temperature, $[\mathrm{K}]$

Blade velocity, $[\mathrm{m} / \mathrm{s}]$

Relative air velocity, [m/s]

Water-to-air ratio, $\left[\mathrm{kgH}_{2} \mathrm{O} / \mathrm{kg}\right.$ air]

Absolute air angle, [deg]

Relative air angle, [deg]

Air density, $\left[\mathrm{kg} / \mathrm{m}^{3}\right]$

Polytropic efficiency

Ratio of specific heats

Stage work coefficient, $\left[(\mathrm{kJ} / \mathrm{kg}) /(\mathrm{m} / \mathrm{s})^{2}\right]$

Flow coefficient

Axial velocity component

Ambient condition

$\begin{array}{ll}\text { mix } & \text { Mixture (humid air) } \\ \mathrm{s} & \text { Static condition } \\ \mathrm{t} & \text { Total condition } \\ \mathrm{tip} & \text { Tip } \\ \mathrm{VMD} & \text { Volume median diameter } \\ \mathrm{w} & \text { Tangential velocity component } \\ 2.1,2.2, \ldots 2.7 & \text { Compressor stage } 1,2, \ldots \text { to stage } 7 \\ 3 & \text { Compressor discharge } \\ 5 & \text { Turbine discharge }\end{array}$

\section{TEST FACILITIES AND ENGINE DESCRIPTION}

Engine testing was carried out at the RNoAF's test facilities at Kjeller, Norway.

The General Electric J85-13 engine is a compact, light weight, single-spool turbojet engine. It has an eight-stage axialflow compressor with bleed-off valves, adjustable inlet guide vanes and a variable exhaust nozzle. The compressor pressure ratio is $6.5: 1$. The variable geometry is controlled by the throttle angle, but the timing is ambient temperature biased. At ISO conditions, IGV will be at maximum deflection and bleed-offvalves will be fully open below $\sim 81 \%$ corrected speed and fully closed at $>96 \%$ corrected speed. At ambient temperatures above ISO conditions, the bleed-off-valves will close at lower speed settings. The nozzle is controlled by the throttle as long as the engine is running below the exhaust temperature limit. When the maximum exhaust temperature is reached, the exhaust nozzle will increase the flow. This reversal in the exhaust nozzle schedule occurs close to the maximum throttle angle.

GE J85-13 compressor geometry is published by Tesch and Steenken [13] and compressor stage characteristics are published by Milner and Wenzel [14].

\section{ENGINE INSTRUMENTATION}

Additional sensors were installed to provide more information than available from standard test-cell instrumentation. The engine instrumentation is shown in Fig. 1.

The temperatures at stages 1, 3, 4, 6 and 8 were measured using a single resistance temperature detector (RTD) at each stator row. The entire $15 \mathrm{~mm}$ sensor length was immersed into the airflow, giving a representative measure of the bulk average temperature. Because the sensors are unshielded, the velocity error will be significant in the temperature reading. The velocity error was calculated as recommended in AGARD AR-245[15] with a recovery factor of 0.65 .

The static pressures at stage 5 and at compressor discharge were measured at a single point on the circumference. The stage 5 static pressure was measured in the bleed channel.

\footnotetext{
${ }^{*}$ ISO reference conditions assume an ambient temperature of 288.15 $\mathrm{K}$, a barometric pressure of $101.325 \mathrm{kPa}$ and a relative humidity of $60 \%$.
} 


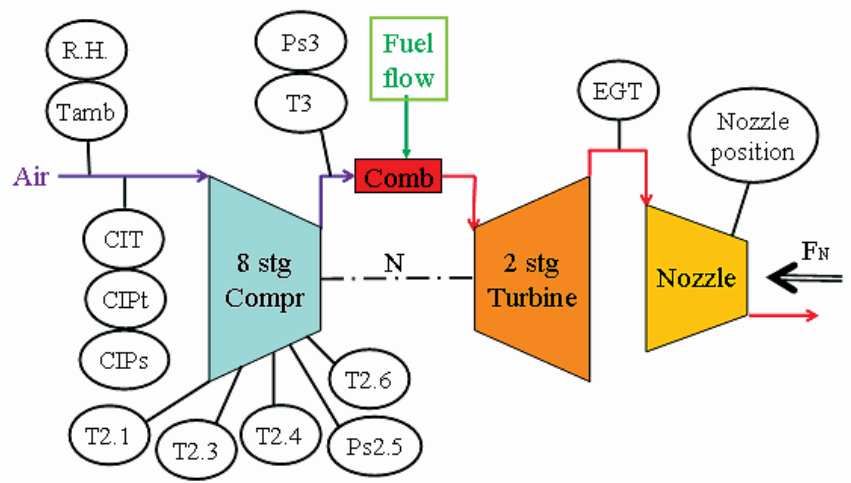

Figure 1 GE J85-13 engine instrumentation

Engine throttle and nozzle position were recorded manually at each setting. Relative humidity and ambient temperature were recorded manually throughout the testing and were measured at the same location outside of the test-cell intake. Due to test-cell recirculation, the recorded compressor inlet total temperature (CIT) was slightly higher than the measured ambient temperature. CIT was measured using four sensors located at the engine inlet screen.

All instruments were calibrated prior to the test program and the measurement uncertainties were calculated based on methods given in the ASME Performance Test Codes [16,17].

\section{ENGINE ONLINE WATER WASH EQUIPMENT}

Accelerated engine deterioration was done through the ingestion of atomized saltwater[18]. Further details of the deterioration method, equipment and results are given in Syverud, Brekke \& Bakken[12].

The online water wash system consisted of a water manifold with nozzles positioned $0.77 \mathrm{~m}$ in front of the compressor IGV. Two different manifolds were used, one with 12 air assisted, flat spray nozzles with a droplet size of $25 \mu \mathrm{m}_{\mathrm{VMD}}$, the other with provisions for up to 18 full cone spray nozzle tips with a droplet size of $75 \mu \mathrm{m}_{\mathrm{VMD}}$ or $200 \mu \mathrm{m}_{\mathrm{VMD}}$. The number of nozzles in each test was selected to give comparable flow rates for the different cases. The pictures in Fig. 2 and 3 show the two water manifolds with comparable water flow rates. Both water wash manifold provide a good coverage of the droplets across the annulus and the injection direction and closeness to the engine bellmouth allows for good control of the droplet sizes at the compressor face. The injection velocity is greatest for the larger droplets (75 and $200 \mu \mathrm{m})$.

The droplet sizes were measured using a Malvern laser diffraction spray analyzer in still air and applying the ASTM Standard E799-92 for calculating spray characteristics[19]. The measurements were taken at the center of the fully developed spray at a distance of $44 \mathrm{~cm}$ from the nozzles. As the nozzles were closely separated and tilted towards the centerline, the droplet size changed slightly depending on the number of nozzles used. The droplet size could not be measured in the largest flow rates due to multiple scattering of the laser beam. The measured droplet size is reported in Table 3 together with the droplet size data provided by the manufacturer. In the following, the water nozzles are referred to using the droplet sizes provided by the manufacturer

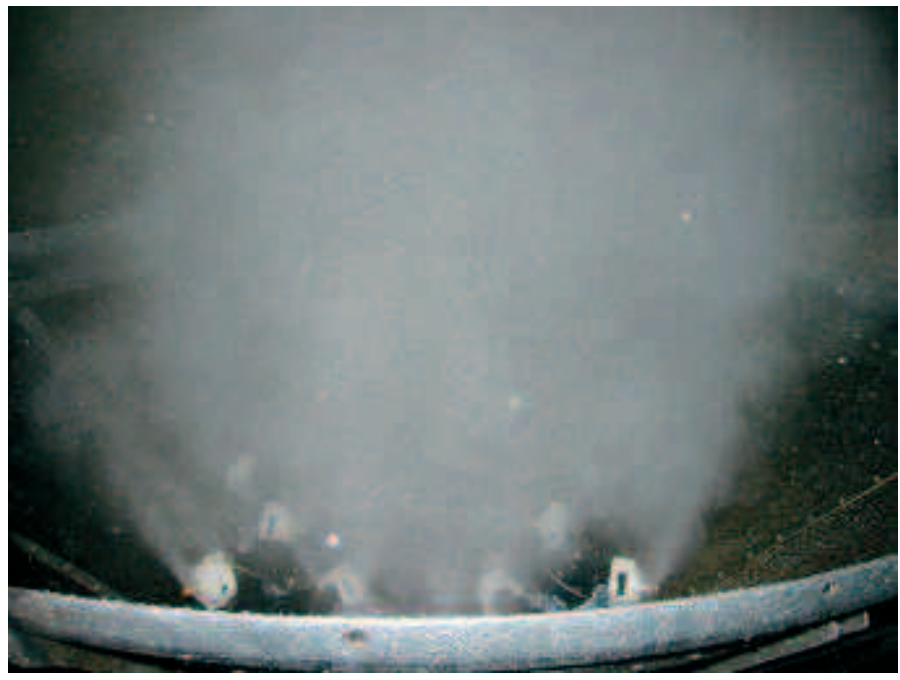

Figure 2 Water wash manifold with 12 nozzles giving $25 \mu \mathrm{m}_{\mathrm{VMD}}$ droplets at $4.4 \mathrm{l} / \mathrm{min}$

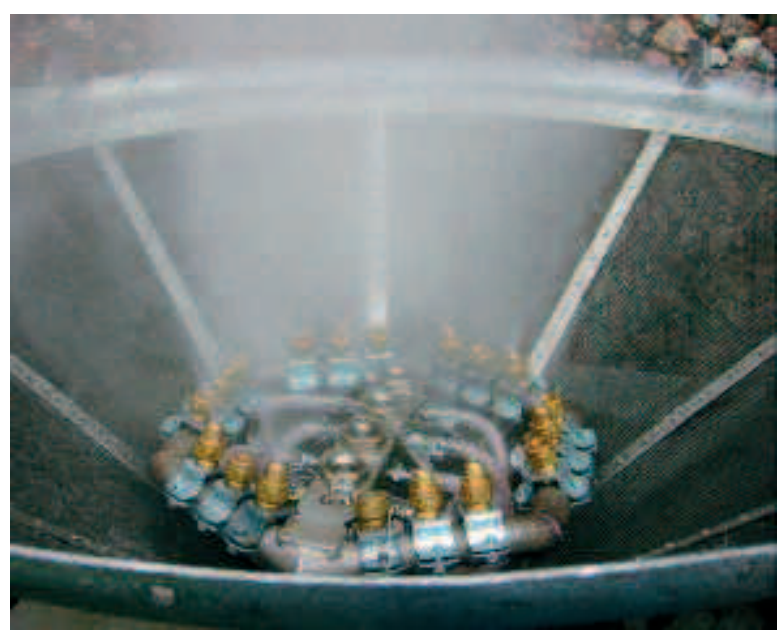

Figure 3 Water wash manifold with eight nozzles giving $75 \mu \mathrm{m}_{\mathrm{VMD}}$ droplets at $4.3 \mathrm{l} / \mathrm{min}$

The water was supplied at 24 bar pressure. Water flow rates were measured using a turbine flow meter. Figure 4 shows the schematics of the water wash system with air assisted nozzles given in Fig. 2. The manifold shown in Fig. 3 is run at full water pressure from the pump, and with no air assistance. 


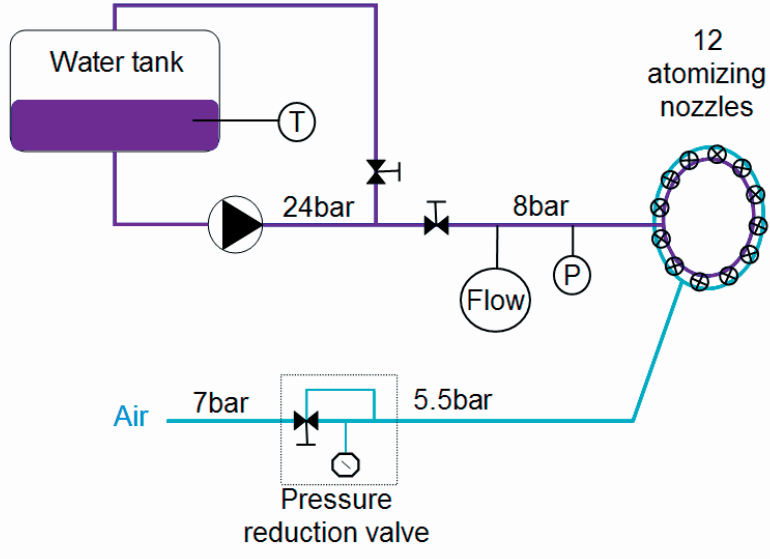

Figure 4 Water wash system schematics (air assisted nozzles)

Tap water with no additives or detergents was used in all tests. The results from water analysis are given in Table 1. For field online washing, the water quality must be conforming to the requirement of the gas turbine manufacturer.

\section{Table 1 Analysis of water used for online water wash}

\begin{tabular}{|l|l|}
\hline Total matter & $<1 \mathrm{mg} / 1$ \\
\hline $\mathrm{pH}$ & 7.52 \\
\hline Sodium & $2.1 \mathrm{ppm}$ by weight \\
\hline Potassium & $0.63 \mathrm{ppm}$ by weight \\
\hline Cloride & $1.7 \mathrm{ppm}$ by weight \\
\hline
\end{tabular}

\section{TEST PROCEDURE}

The engine baselines were established for steady-state operation at 12 operating points from $60 \%$ corrected speed to full load. Prior to establishing each baseline, the engine was run for 5 minutes at full load. Engine speed was then reduced to idle before being increased to the initial throttle setting. At each throttle setting, the engine was allowed to stabilize for 1 minute before reading 60 data points. To prevent impact of hysteresis from the instrument or control system, all throttle settings were established at increasing engine speeds. Engine baselines were recorded prior to degradation, after salt degradation, and after each online water wash.

All salt degradation trials were run at $10^{\circ}$ throttle angle (equivalent to $97.5 \%$ engine shaft speed) at constant nozzle position and with closed bleed-off-valves and fully open IGV.

To completely clean the compressor of salt deposits, a 5 minute online water wash was done at engine speeds varying from full speed to idle for two complete cycles using 17.6 liters of water per minute (droplet size of $200 \mu \mathrm{m}$ ).

Seven online water wash tests were completed. The test matrix is given in Table 3. Engine performance was measured after $30 \mathrm{sec}, 60 \mathrm{sec}, 90 \mathrm{sec}, 4$ minutes and 10 minutes online water wash.
Table 2 Test matrix

\begin{tabular}{|c|c|c|c|c|}
\hline $\begin{array}{c}\text { Test } \\
\text { number }\end{array}$ & $\begin{array}{c}\text { Droplet size }\left(\boldsymbol{\mu \mathbf { m } _ { \text { VMD } } )}\right. \\
\text { by } \\
\text { manufacturer }\end{array}$ & $\begin{array}{c}\text { Water } \\
\text { measured }\end{array}$ & $\begin{array}{c}\text { Water-to- } \\
\text { flow rate } \\
\text { air ratio }\end{array}$ & \\
\hline 1 & 200 & -- & 30.9 & $3.0 \%$ \\
\hline 2 & 200 & -- & 17.6 & $1.7 \%$ \\
\hline 3 & 200 & 131 & 8.8 & $0.87 \%$ \\
\hline 4 & 200 & 139 & 4.4 & $0.43 \%$ \\
\hline 5 & 75 & 83 & 9.1 & $0.89 \%$ \\
\hline 6 & 75 & 93 & 4.3 & $0.42 \%$ \\
\hline 7 & 25 & 39 & 4.4 & $0.43 \%$ \\
\hline
\end{tabular}

\section{RESULTS}

The engine performance deterioration and restoration was analyzed through changes in the intake depression and in the compressor stage work coefficient. Intake depression is defined as the deviation between the total and static pressure at engine inlet. Detailed background on the stage performance calculations is given in Syverud, Brekke and Bakken [12], and will not be repeated in here, since the only difference is the blockage factor which is set to 1.0 for all cases presented in this paper.

The presented test data are limited to engine operation above $95 \%$ engine shaft speed where the engine bleed-offvalves were closed and the IGV were fully open.

The test data are compared to the stage work coefficient found in literature [14]. Those data are based on constant values for $c_{\mathrm{p}}(1005 \mathrm{~J} / \mathrm{kgK})$ and $\gamma(1.4)$, while in here; the gas properties are dependent on gas temperature and humidity. The difference will be largest in the aft stages where the gas temperatures are at the highest. Still, the published data give a good indication of the GE J85-13 stage performance for a large range of flow coefficients. 


\section{Water-to-air ratio}

The GE $\sqrt{85}-13$ was operated without stability or structural problems at water injection rates of $401 / \mathrm{min}$ at all speeds from $70 \%$ to full speed. This represents mass based water-to-air ratios above $3 \%$ at full speed and $7 \%$ at $70 \%$ speed. However, these very high water-to-air ratios may cause excessive blade loads and potential erosion damage and are not recommended for online water washing.

Figure 5 shows the change in intake depression as a function of corrected engine shaft speed for three different water-to-air ratios with $200 \mu \mathrm{m}$ droplet size and 60 seconds water injection time.

Figure 6 and 7 show the change in stage work coefficient for the same cases as given in Fig. 5. Stage four performance is not restored with the smallest water-to-air ratio of $0.43 \%$. The remaining salt deposits reduce the effective flow area, and cause a reduction in the stage six flow coefficient. With a 3\% water-toair ratio both the fourth stage and the sixth stage performance is completely restored.

The tests clearly document the impact of increased waterto-air ratio on the compressor performance recovery. At low water-to-air ratios, the performance recovery is limited.

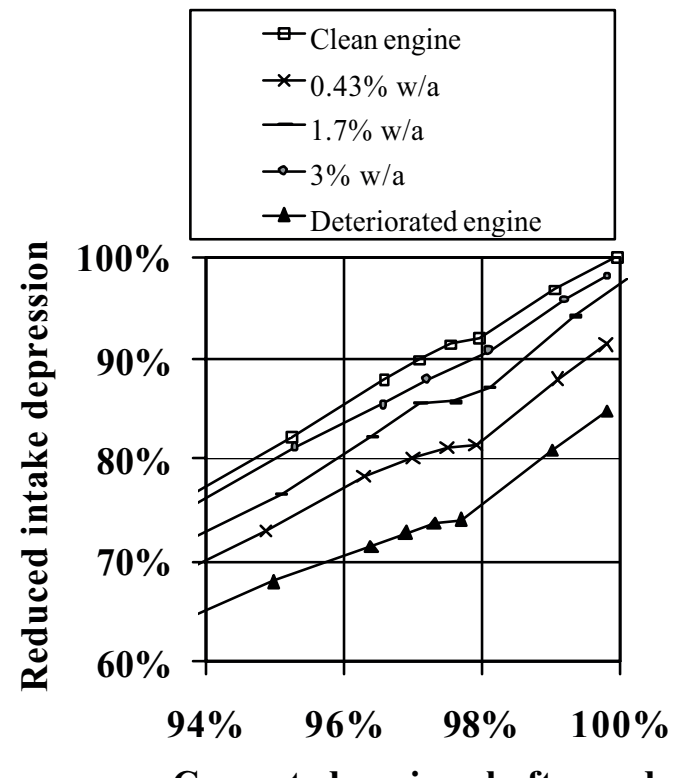

Corrected engine shaft speed

Figure 5. Intake depression recovery after $60 \mathrm{sec}$ water wash with $200 \mu \mathrm{m}$ droplets

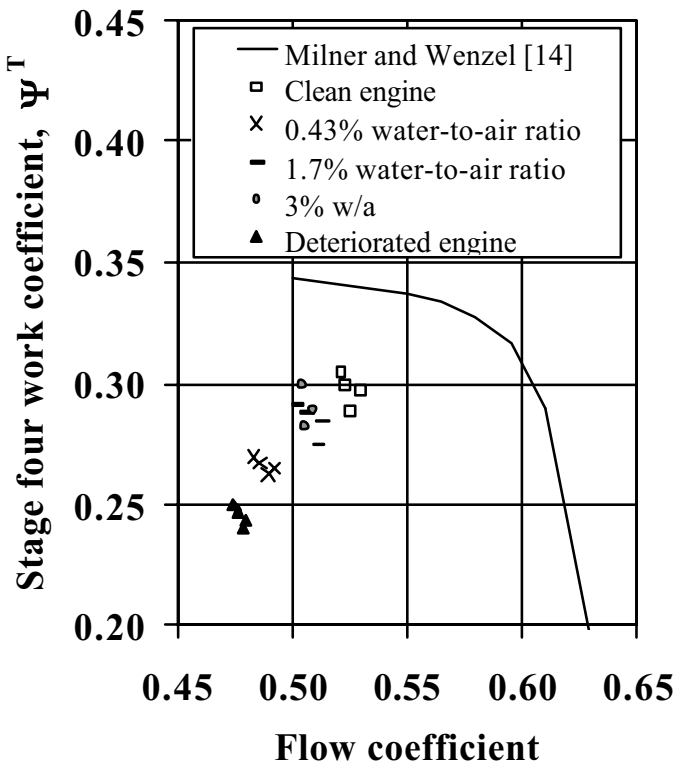

Figure 6. Stage four work coefficient after $60 \mathrm{sec}$ water wash with $200 \mu \mathrm{m}$ droplets

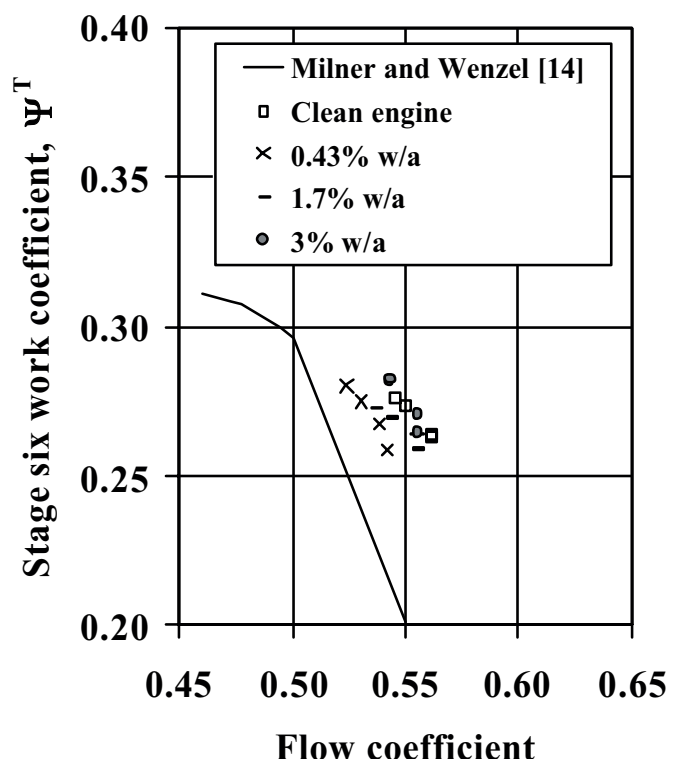

Figure 7 Stage six work coefficient after $60 \mathrm{sec}$ water wash with $200 \mu \mathrm{m}$ droplets 


\section{Water injection time}

Increasing the water injection time of online water wash is expected to improve the performance recovery when the engine is fouled with water soluble components like salt [1].

Figure 8 compares the change in intake depression for three different cases with $200 \mu \mathrm{m}$ droplet size. The total water injected in the 4 minute water wash at $0.43 \%$ water-to-air ratio is equivalent to the total water injected during the $60 \mathrm{sec}$ water wash at $1.7 \%$ water-to-air ratio. The $0.43 \% 60 \mathrm{sec}$ water wash case is included for reference. The impact on stage four and six work coefficients are given in Fig. 9 and 10, respectively.

Although an equivalent mass of water are used in the $1.7 \%$ $60 \mathrm{sec}$ wash and the $0.43 \% 4 \mathrm{~min}$ wash, the increased water injection time at lower flow rate fails to recover the engine performance. With the low water-to-air ratio of $0.43 \%$, the water seems to evaporate in stage four and the expected benefit from increased soaking time is therefore not present.

The tests show that water injection time is only an issue in the front stages where the wash fluid is not evaporated. For aft stage performance recovery, it is better to inject the water in a shorter time, hence, at a higher water-to-air ratio.

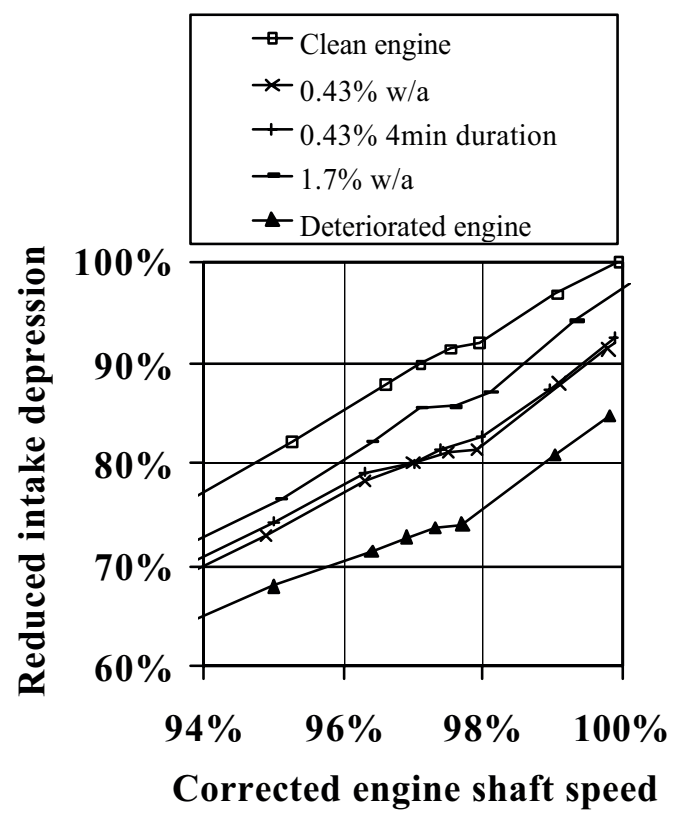

Figure 8. Intake depression recovery at different water injection times with $200 \mu \mathrm{m}$ droplets

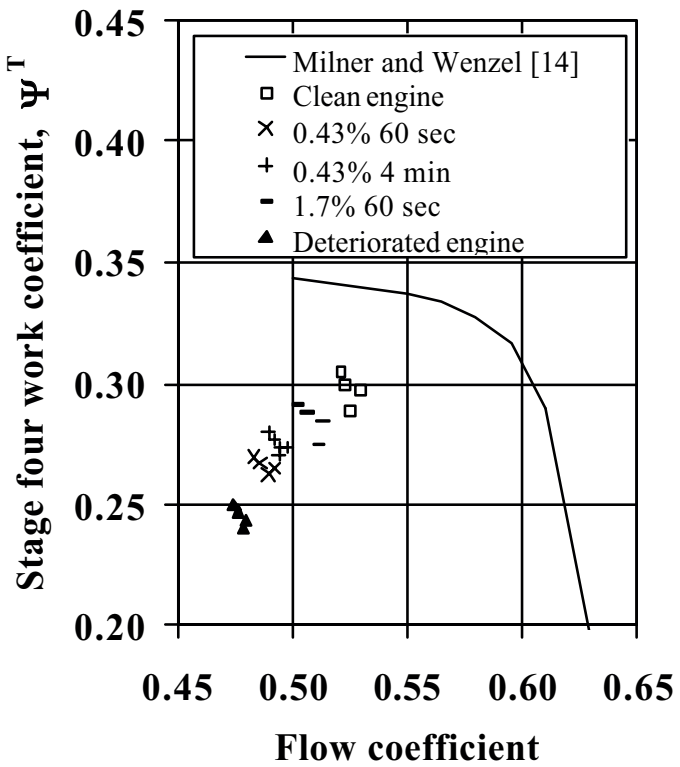

Figure 9. Fourth-stage work coefficient after water wash with $200 \mu \mathrm{m}$ droplets at different water injection times

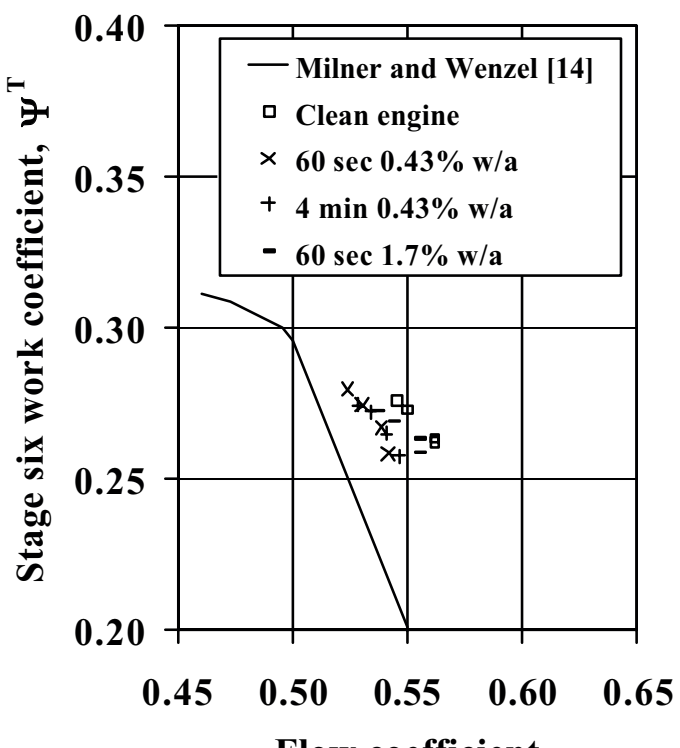

Figure 10 Stage six work coefficient after water wash with $200 \mu \mathrm{m}$ droplets at different water injection times 


\section{Droplet size}

Droplet size is considered important for performance recovery in the aft compressor stages. Water flow path, surface wetting, evaporation rate and erosion are all affected by the droplet size.

Figures 11-13 compare the intake depression restoration and the stage four and six work coefficient recovery after 60 second online water wash at a water-to-air ratio of $0.4 \%$ and with various droplet sizes.

The $75 \mu \mathrm{m}$ droplets are the most effective in recovering the overall engine performance, and in cleaning the fourth-stage; however, the smaller droplets seem to redeposit the fouling in the sixth-stage and cause increased sixth-stage deterioration. The $25 \mu \mathrm{m}$ droplets cause heavy deposits in the sixth-stage and are the least effective in restoring the overall engine performance.

The tests show that small droplets increase the fouling in the aft stages.

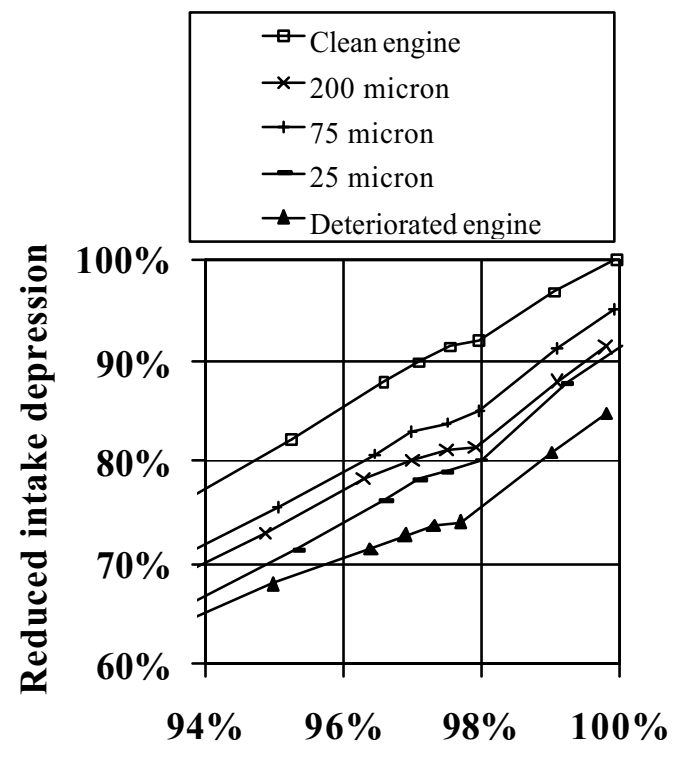

Corrected engine shaft speed

Figure 11 Intake depression recovery after $60 \mathrm{sec}$ water wash with various droplet sizes at $0.4 \%$ w/a.

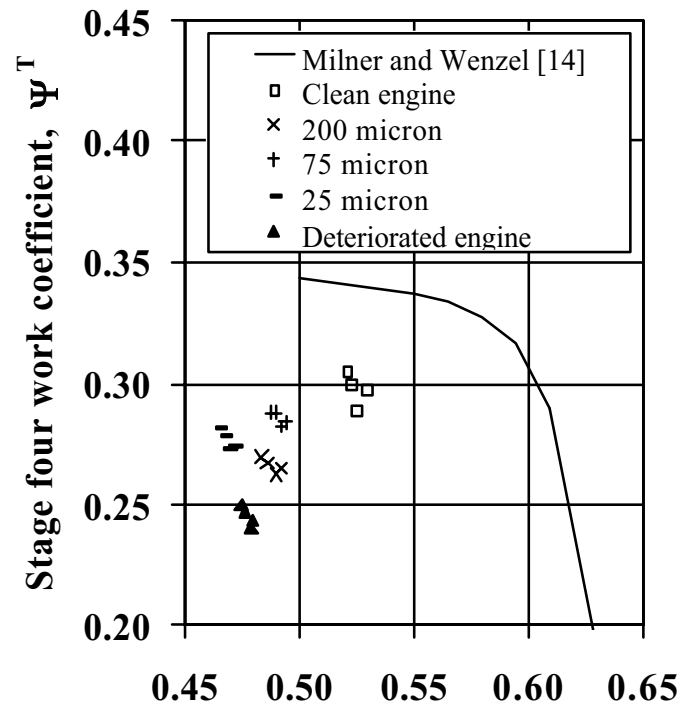

Flow coefficient

Figure 12 Stage four work coefficient after 60 sec water wash at $0.4 \% \mathrm{w} / \mathrm{a}$

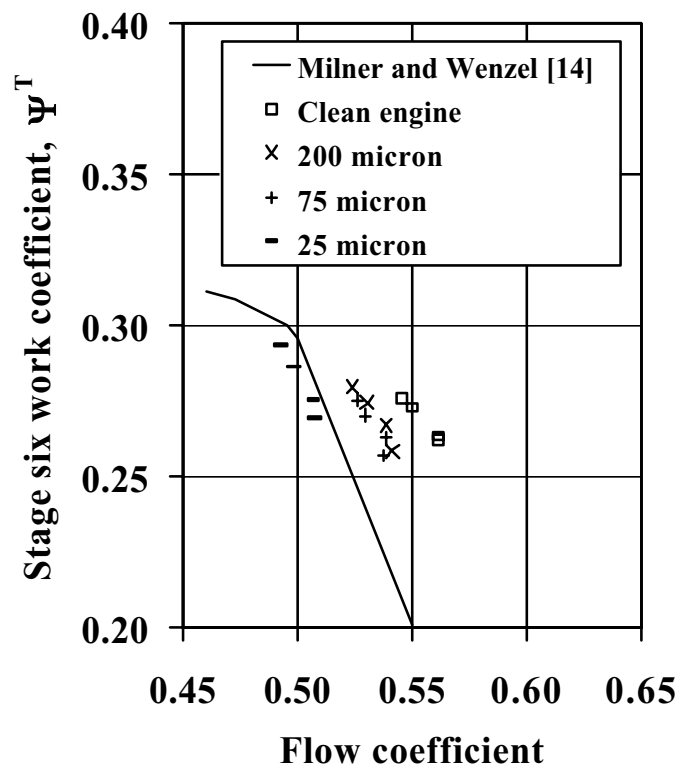

Figure 13 Stage six work coefficient after 60 sec water wash at $0.4 \% \mathrm{w} / \mathrm{a}$

\section{Salt distribution after water wash}

Further evidence of the movement of salt from the front stages to the aft stator vanes is given in Fig. 14. The figure compares the salt deposits on the stator vanes after degradation to the salt distribution after a 60 second water wash with $75 \mu \mathrm{m}$ droplets and $0.42 \%$ water-to-air ratio. The salt deposits were 
measured as chorine content and transformed to weight distribution of salt (sodium chloride).

After degradation immeasurable traces of salt were found on the aft stages. However, after the water wash, the salt had moved from the front stages and aft, redepositing on all stages from stage four.

Rotor deposits were not possible to measure due to practical limitations; however, from visual observation, the salt deposits after water wash were found to be heaviest on the suction side of stage three, four and six and on the pressure side of stage 5 .

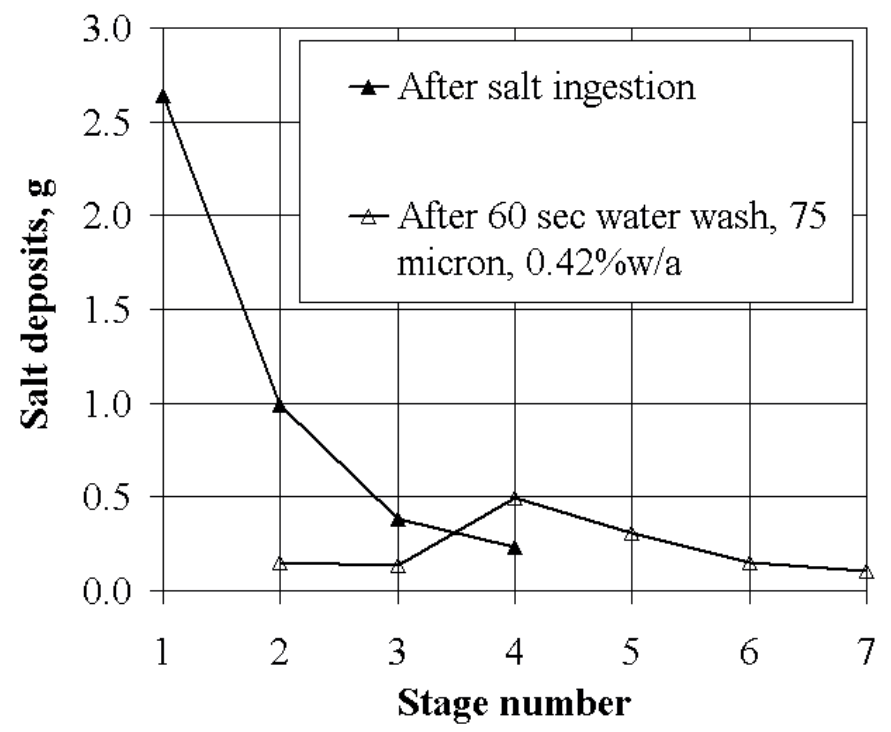

Figure 14 Weight distribution of salt deposits on stator rows

\section{Velocity triangles}

As a visualization of the change in stage loading with deterioration and online water wash, the velocity triangles for stage 4 in the clean, deteriorated and washed conditions are shown in Fig. 15. In the Figure, the blue arrows represent the clean condition, the green arrows the clean condition, and the stippled arrows the deteriorated condition. The data are for the $98 \%$ operating point, where the engine shaft speed varied from 16,204 to 16,162 and $16,208 \mathrm{rpm}$ for clean, deteriorated and washed conditions, respectively. This change in blade speed was negligible when comparing the velocity triangles. The water wash data are for $75 \mu \mathrm{m}$ droplets, $0.42 \%$ water-to-air ratio and 60 sec water injection time. The data are calculated based on the assumptions given above for the calculation of stage work. As discussed above, the deviation angles are assumed constant for the clean and deteriorated cases. Equations for the calculations of velocity triangles are given in Appendix A.
The velocity triangles show that the deterioration causes a reduction in the flow coefficient and a change in the stage work coefficient.

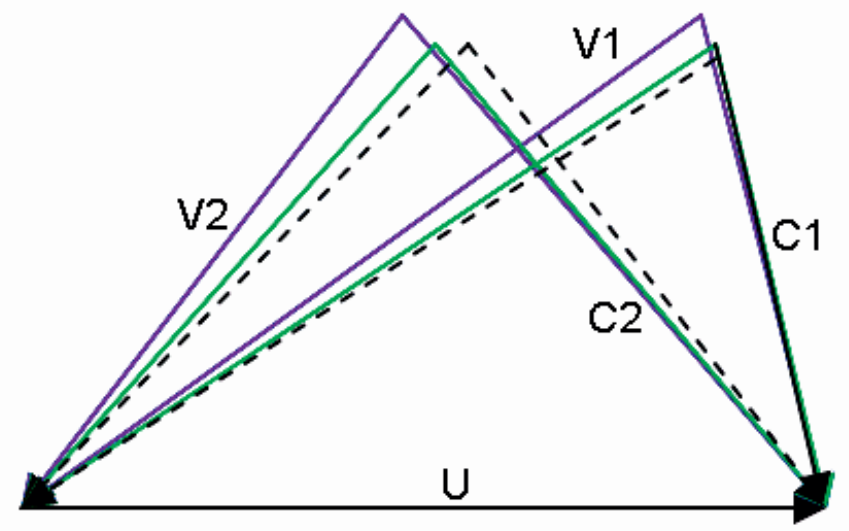

Figure 15 Stage 4 velocity triangles at $98 \%$ shaft speed

\section{CONCLUSIONS}

Online water washing has become increasingly important with operators of industrial gas turbines due to the potential for reduced degradation rate, increased operating intervals and high overall performance.

To reveal the compressor performance deterioration and restoration mechanisms an in-depth test campaign has been performed on a GE J85-13 engine. Based on test results and performance analyses the main mechanisms are:

- High water flow rate is the most significant parameter for effective online water wash.

- Low flow rates cause redeposition of the fouling in the aft stages.

- Increased water injection time cannot compensate for low flow rates.

- Smaller droplets increase the fouling in the aft stages.

For effective water washing of the entire compressor section the recommended water-to-air ratio is between 0.8 to $2 \%$. Droplet diameters up to $200 \mu \mathrm{m}$ have been tested. The maximum droplet size and water-to-air ratio should be determined with close attention to blade erosion and other long term mechanical and structural problems.

The present achievements will be followed by field tests on a Rolls-Royce RB 211 in an offshore application.

\section{ACKNOWLEDGMENTS}

The project has been supported by Statoil ASA, DresserRand Norwegian Operations and the Royal Norwegian Navy. The Royal Norwegian Air Force is acknowledged for allowing access to their test facilities and for allowing us to borrow a GE J85-13 for test purposes. Without the help of Mr. Hans K. 
Henriksen, a retired test-cell operator of the RNoAF this project would never have come to fruition.

\section{REFERENCES}

[1] Stalder, J.-P., 2001, "Gas turbine compressor washing state of the art: Field experiences," ASME Journal of Engineering for Gas Turbines and Power, Vol.123, April, pp.363-370.

[2] Mund, F., Pilidis, P., 2004, "A review of online washing systems," Proceedings of ASME Turbo Expo 2004, June 1418, Vienna, Austria, GT2004-53224.

[3] Asplund, P., 1997, "Gas turbine cleaning upgrade (compressor wash)," ASME ASIA'97 Congress and Exhibition, Singapore, Sept. 30- Oct. 2, ASME 97-AA-135.

[4] Asplund, P. and Hjerpe, C.J., 2004, "A method for cleaning a stationary gas turbine unit during operation," World Patent No. WO2004/055334.

[5] Faddegon, C.J., 1999, "Effective compressor cleaning as a result of scientific testing and field experience," FP Turbomachinery Consultants GmbH, Spinzalaan 177-C, 2273 XG Voorburg, the Netherlands.

[6] Marchik.A., 1965, "Motion of condensed phase in the blade passages of an axial gas turbine stage," Teploenergetika, pp. 51-57.

[7] Tsuchiya, T. and Murthy, S.N.B., 1982, "Water ingestion into jet engine axial compressors," American Institute of Aeronautics and Astronautics, 82-0196.

[8] Horlock, J.H., 2001, "Compressor performance with water injection," Proceedings of ASME Turbo Expo 2001, June 4-7, 2001, New Orleans, Louisiana.

[9] Young, J.B., "The fundamental equations of gas-droplet multiphase flow," Int. Journal of Multiphase Flow, pp.175191, 1995.

[10] Meacock, A.J. and White, A.J., 2004, "The effect of water injection on multi-spool gas turbine behavior," ASME Proceedings of Turbo Expo 2004, June 14-17, Vienna, Austria, ASME GT2004-53320.

[11] Garwood, K.R. (chair), 1995, "Recommended practices for the assessment of the effects of atmospheric water ingestion on the performance and operability of gas turbine engines," AGARD Advisory Report AGARD AR-332.

[12] Syverud, E., Brekke, O. and Bakken, L.E., 2005, "Axial compressor deterioration," ASME Proceedings of GT2005, June 6-9, Reno-Tahoe, NV, ASME GT2005-68701.

[13] Tesch W.A., and Steenken, W.G., 1976, "Blade row Dynamic digital compressor program Volume 1 J85 clean inlet flow and parallel compressor models", NASA CR-134978.

[14] Milner, E.J., and Wenzel, L.M., 1975, "Performance of a J85-13 compressor with clean and distorted inlet fow," NASA TM X-3304.

[15] Saravanamuttoo, H.I.H. (ed.), 1990, "Recommended practices for measurement of gas path pressures and temperatures for performance assessment of aircraft turbine engines and components," AGARD Advisory Report AGARD AR-245.
[16] ASME PTC-22, 1997, "Performance test code on gas turbines."

[17] ASM E PTC-19.1, 1998, "Test uncertainty."

[18] Caguiat, D.E., Zipkin, D.M., and Patterson, J.S., 2002, "Compressor fouling testing on Rolls Royce/Allison 501K17 and General Electric LM 2500 gas turbine engines", Proceedings of ASME Turbo Expo 2002, June 3-6, Amsterdam, the Netherlands, GT2002-30262.

[19] ASTM Standard E 799-92, 1992, "Standard practice for determining data criteria and processing for liquid drop size analysis," ASTM International, West Conshohocken, PA.

\section{APPENDIX A: EQUATIONS FOR CALCULATIONS OF VELOCITY DIAGRAM}

Data for the velocity diagram are readily available from the iterative calculation of stage performance, described in Syverud, Brekke and Bakken [5].

1. The absolute air velocities and the blade velocity are known from the stage performance calculations at the rotor inlet: $\mathrm{C}_{\mathrm{a} 1}, \mathrm{C}_{1}, \mathrm{C}_{\mathrm{w} 1}, \mathrm{U}_{1}$.

2. The relative velocity at rotor inlet is calculated from:

$$
V_{w 1}=U_{1}-C_{w 1} \quad, \quad V_{1}=\sqrt{V_{w 1}^{2}+C_{a 1}^{2}}
$$

3. The tangential blade velocity at rotor outlet is given by:

$$
\mathrm{U}_{2}=2 \pi r_{2} \frac{\mathrm{N}}{60}
$$

4. The tangential component of the absolute velocity at rotor outlet is given by the change in work coefficient:

$$
C_{w 2}=\frac{c_{p 1}\left(T_{t 2}-T_{t 1}\right)+C_{w 1} U_{1}}{U_{2}}
$$

5. Consequently, the absolute velocity at rotor outlet is:

$$
C_{2}=\sqrt{C_{w 2}^{2}+C_{a 2}^{2}}
$$

6. And the relative velocity at rotor outlet is given by:

$$
V_{w 1}=U_{1}-C_{w 1} \quad, \quad V_{1}=\sqrt{V_{w 1}^{2}+C_{a 1}^{2}}
$$

7. Knowing the velocity vectors, the absolute and relative air angles at rotor inlet and outlet are given from geometry:

$$
\alpha=\operatorname{atan}\left(\frac{C_{w}}{C}\right) \quad, \quad \beta=\operatorname{atan}\left(\frac{V_{w}}{V}\right)
$$

8. The stator exit velocity is found from assuming zero deviation in the stator blade exit angle: $C_{a 3}=\frac{\dot{m}}{\rho_{3} A_{3}} \quad, \quad C_{3}=C_{a 3} \cos \left(\alpha_{3}\right)$ 